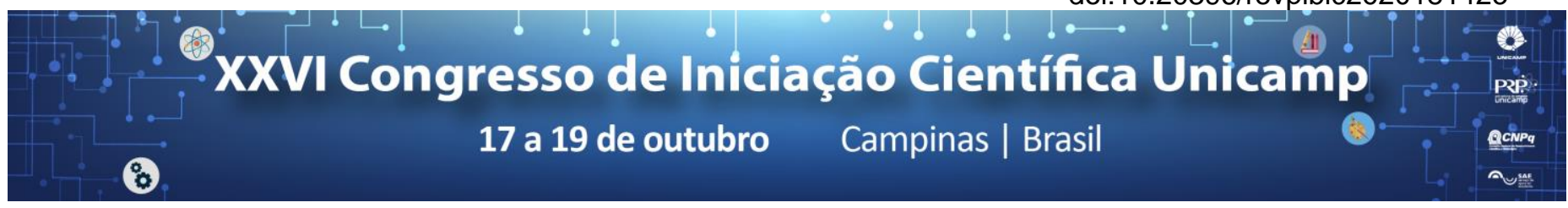

\title{
Avaliação discente sobre $o$ uso de quizzes e jogos educacionais no ensino de fisiologia
}

\section{Anna Clara R. Guarnieri, Beatriz S. Silva*, Ricardo S. Sleimann Jr. ${ }^{\star}$, Lais T. Cardozo, Fernanda K. Marcondes}

\section{Resumo}

A fim de promover maior participação dos alunos, nas aulas de Fisiologia do curso de Odontologia da Faculdade de Odontologia de Piracicaba têm sido utilizados quizzes e jogos educacionais, como estratégias ativas de ensinoaprendizagem. O objetivo deste estudo foi estudar como os alunos avaliam o efeito destas metodologias no seu aprendizado sobre temas de fisiologia humana. As atividades com quizzes e jogos educacionais foram utilizados de forma combinada com aulas teóricas sobre fisiologia dos sistemas cardiovascular e renal. O objetivo deste estudo foi avaliar se, na percepção dos alunos, os jogos educacionais e quizzes facilitam o aprendizado.

\section{Palavras-chave:}

Ensino, fisiologia, jogo educacional

\section{Introdução}

- Aulas teóricas como única estratégia de ensino tem se mostrado ineficientes e desmotivadoras.

- Quizzes e jogos educacionais promovem maior participação e interação dos alunos, aumentam o seu interesse e tornam a aula mais dinâmica e agradável.

- Nas aulas de Fisiologia, ministradas no curso de Odontologia da FOP - UNICAMP, estas estratégias têm sido utilizadas no ensino de Fisiologia cardiovascular e renal.

- O objetivo deste estudo foi avaliar se, na percepção dos alunos, os jogos educacionais e quizzes facilitam o aprendizado.

\section{Resultados e Discussão}

No início do semestre seguinte, os alunos foram convidados a responder uma questão sobre sua opinião sobre estas atividades. Para a avaliação do jogo educacional, foi solicitado aos alunos $(\mathrm{N}=62)$ que indicassem entre 4 alternativas, se a atividade não ajudou, ajudou mas não foi necessária para a compreensão do conteúdo, ajudou, complementando o que havia sido compreendido ou foi fundamental para a compreensão do tema. Para $100 \%$ dos alunos, o jogo educacional ajudou no aprendizado.

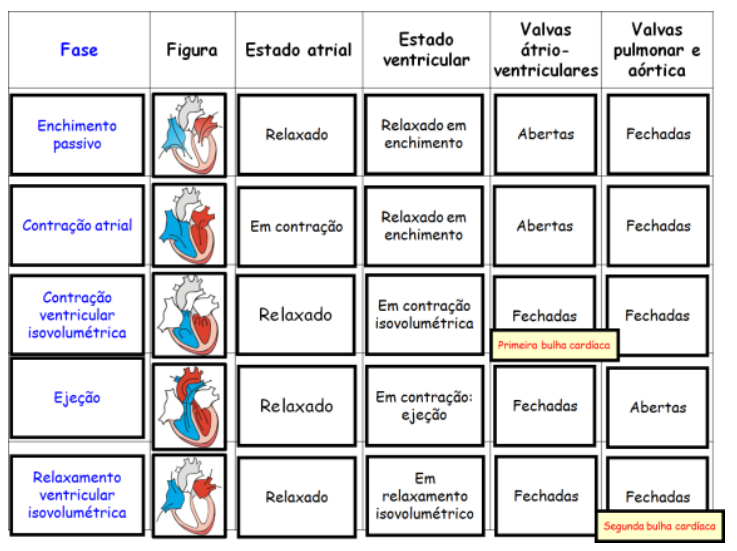

Figura 1. Jogo educacional sobre fisiologia cardíaca.
Tabela 1. Respostas dos alunos sobre o jogo educacional utilizado para o ensino de fisiologia cardíaca.

\begin{tabular}{|c|c|c|}
\hline Alternativas & $\mathrm{N}$ & $\%$ \\
\hline $\begin{array}{l}\text { a) Não ajudou no meu aprendizado. Ela foi } \\
\text { desnecessária para eu compreender o conteúdo } \\
\text { estudado, porque eu já havia entendido a matéria } \\
\text { com as aulas teóricas e estudo no livro indicado. } \\
\text { A atividade não precisaria ter sido realizada. }\end{array}$ & 0 & 0 \\
\hline $\begin{array}{l}\text { b) A atividade ajudou no meu aprendizado, mas } \\
\text { não foi necessária para eu compreender todo o } \\
\text { conteúdo estudado. Ela foi útil porque me } \\
\text { ajudou a perceber que eu havia de fato } \\
\text { entendido o conteúdo. }\end{array}$ & 5 & 8 \\
\hline $\begin{array}{l}\text { c) A atividade ajudou no meu aprendizado, } \\
\text { tendo sido necessária para eu compreender } \\
\text { melhor parte do conteúdo. Embora eu tivesse } \\
\text { compreendido grande parte do conteúdo } \\
\text { estudado, a atividade me ajudou a tirar dúvidas } \\
\text { e esclarecer alguns pontos que eu não tinha } \\
\text { compreendido bem. }\end{array}$ & 44 & 71 \\
\hline $\begin{array}{l}\text { d) A atividade foi fundamental para o meu } \\
\text { aprendizado. Esta atividade foi necessária para } \\
\text { eu compreender o conteúdo, que somente com } \\
\text { a aula e o estudo no livro, eu não tinha } \\
\text { compreendido. }\end{array}$ & 13 & 21 \\
\hline
\end{tabular}

Para avaliação dos quizzes, os alunos $(\mathrm{N}=46)$ indicaram numa escala de Likert, de 1 a 5 , se a atividade foi útil para o seu aprendizado, sendo $1=$ desnecessário para 0 aprendizado, e 5 = fundamental para o aprendizado. A média da resposta dos alunos referente aos quizzes foi $3,57 \pm 1,31$.

\section{Conclusões}

Os resultados obtidos mostram que os quizzes e os jogos educacionais foram considerados úteis para o aprendizado, na avaliação discente.

\section{Agradecimentos}

Os autores agradecem 0 suporte financeiro do FAEPEX/UNICAMP e da American Physiological Society (2017 Teaching Career Enhancement Award), pelos auxílios concedidos à professora orientadora FKMarcondes. 